\title{
Vertical bundles of the white matter fibers in the pons revisited: preliminary study utilizing the Klingler technique
}

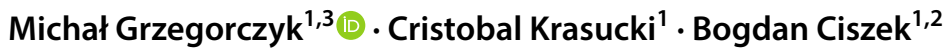

Received: 31 March 2018 / Accepted: 16 October 2018 / Published online: 28 October 2018

(c) The Author(s) 2018

\begin{abstract}
The inner structure of the pons contains several layers of transverse and vertical fibers and many nuclei. The vertical bundles are described as fibers of the corticospinal tract, corticonuclear tract, frontopontine tract and parieto-temporopontine tract organized in three layers. The aim of this study was to investigate the structure of the vertical bundles in the ventral pons using the modified Klingler method. Ten brain stem specimens were investigated. Specimens were fixed in $10 \%$ formalin, frozen for $24 \mathrm{~h}$ to separate nerve fibers by ice crystals, and then unfrozen again in 10\% formalin solution. Afterwards, the specimens were dissected using a sharpened spatula. Results point to the existence of three main layers of vertical bundles and a small, constant, and superficial fourth fascicle that is yet to be described in the literature. We propose the name fasciculus longitudinalis superficialis (superficial longitudinal fascicle) for this group of vertical fibers of the pons.
\end{abstract}

Keywords Pons $\cdot$ Corticospinal tract $\cdot$ Anatomy $\cdot$ Klingler technique $\cdot$ Brain stem

\section{Introduction}

The inner structure of the pons is very complex, given that this compact structure contains many crossing neural tracts as well as many nuclei. Frontopontine (FPT), corticospinal (CST), parieto-temporopontine (PTT), corticonuclear $(\mathrm{CNT})$, and cerebellopontine $(\mathrm{CrPT})$ tracts are found in the ventral pons. These tracts are constructed from vertical (FPT, CST, CNT, and PTT) and transverse (CrPT) nerve fibers which cross each other in an inconstant manner (Clara 1959; De Simone et al. 2005; Fernández-Gil et al. 2010; Oh et al. 2003; Standring et al. 2008). The CST is located in the ventrolateral part of the pons. It is arranged in bundles of vertical fibers separated by transverse fibers and pontine nuclei. It is important to note that CST fascicles maintain somatotopic order along their course through the pons (Fernández-Gil et al. 2010; Hong et al. 2010; Hua et al. 2012; Jang 2011; Prats-Galino et al. 2012). Knowledge of

\section{Michał Grzegorczyk}

1 Department of Descriptive and Clinical Anatomy, Medical University of Warsaw, Warsaw, Poland

2 Department of Neurosurgery, Boganowicz Children Hospital, Warsaw, Poland

3 Warsaw, Poland the precise anatomical localization of a lesion affecting the pons is crucial to the neurological diagnosis, but imaging a small and compact structure such as the pons or some other part of the brain stem remains problematic due to its complexity (Fernández-Gil et al. 2010; Jang 2011; Skadorwa et al. 2009). Pathologies that may require neurosurgical interventions, such as tumors or cavernous hemangiomas, should be localized in relation to the CST to avoid serious postoperative complications. However, even with modern tractography, this can be a difficult task (Kwon et al. 2011). It is therefore essential to localize the individual neural tracts in the pons.

\section{Aim}

The aim of this study was to investigate the spatial arrangement of the vertical nerve fibers in the pons.

\section{Materials and methods}

Ten human brain stem specimens of both sexes (five women, five men) aged 21-90 years were investigated using the modified Klingler method. The specimens, fixed in $10 \%$ formalin, were placed in a freezer at a temperature of $-20{ }^{\circ} \mathrm{C}$ 
for $24 \mathrm{~h}$. The frozen specimens were then placed in $10 \%$ formalin solution again. After $24 \mathrm{~h}$, the specimens were dissected in layers using a sharpened spatula and an anatomical needle under a surgical microscope with a magnification of up to $40 \times$. After the removal of each nerve fiber layer, photographic documentation was carried out using a Fujifilm Finepix S1000FD camera.

\section{Results}

All of the specimens presented three main layers of vertical bundles in the ventral pons, which were separated by layers of transverse fibers (Fig. 1). In nine of the ten specimens (four women and five men), a small vertical superficial fascicle was observed. This fascicle was present on both sides of the pons in eight of those specimens. Altogether, this fascicle was present in 17 of the 20 sides investigated. This superficial vertical fascicle varied in course, size, and the number of smaller fascicles from which it was formed. It was homogeneous in six of the ten specimens dissected with a spatula, whereas it was composed of a number of smaller fascicles (varying from four to two) in three of the specimens (Fig. 2). The course of the superficial vertical fascicle was straight and ventral in four specimens, medioventrally diagonal in two cases, arcing to the lateral side of the pons in another two cases, and lateroventrally diagonal in the remaining case (Fig. 3). In all cases, the fascicle ran ventrally from the mesencephalon to the lower pons and merged with deeper vertical fascicles in its terminal segment.
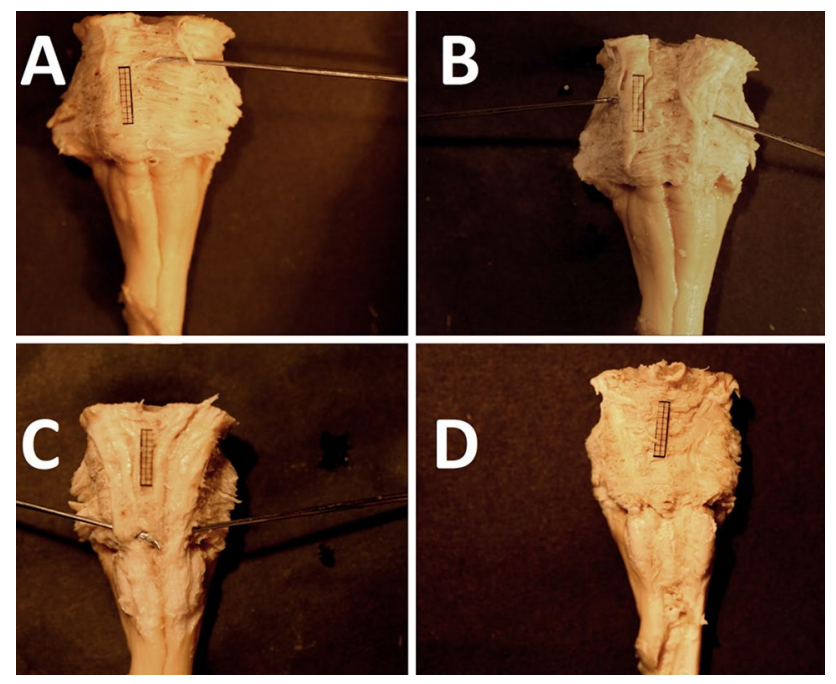

Fig. 1a-d Dissection of the layers of the pons to examine fascicles: a SLF; b FPT; c CST; d PTT

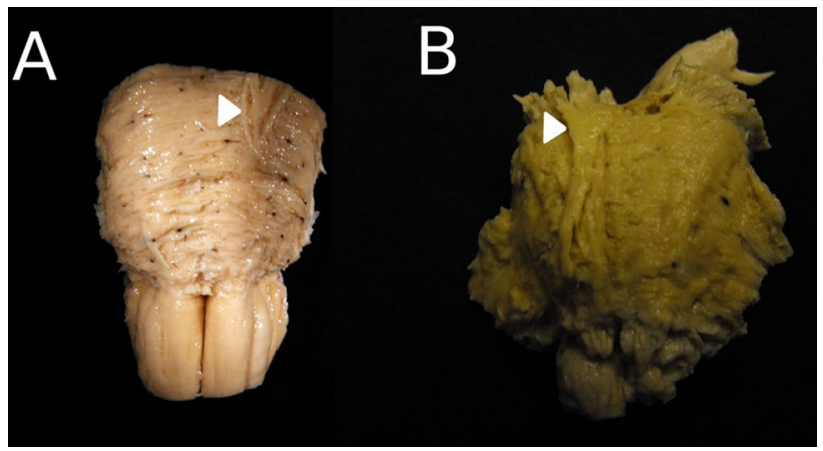

Fig. 2a-b Variations in superficial longitudinal fascicle (SLF; arrowhead) structure: a lesser fascicles that form the SLF; $\mathbf{b}$ homogeneous fascicle

\section{Discussion}

Studying the pons is a difficult task due to the large number of structures and crossing fibers located in such a small space. Although in vivo imaging techniques are commonly used to examine brain structures, such methods still unable to fully visualize the small, independent nerve fiber bundles that are present in the ventral part of the pons (Kwon et al. 2011; Virta et al. 1999). Recently, the importance of white matter dissection using the Klingler method was stressed, as it provides a means to validate the results of diagnostic imaging (Liakos and Koutsarnakis 2016). Indeed, although Zemmoura (2016) claimed that it is more important for a radiologist to carry out diffusion tractography with different tractography tools while appreciating their limitations than to perform dissection, dissection remains an important source of new anatomical information and discoveries. For example, an electron microscopy study of human white matter performed by the same author (Zemmoura 2016) showed that myelinated axons are preserved during Klingler's dissection, which provides strong support for the idea of validating tractography using this method. This may be supported by neuronavigation (Skadorwa et al. 2009). In this approach, dissection is validated by navigation or navigation is validated by dissection.

In the present study, during the layer-by-layer removal of the nerve fibers, the vertical nerve fibers in the ventral pons were observed to be arranged in three main layers, as also noted previously by other authors. The layers are arranged in the order FPT, CST, PTT (Fig. 4), with FPT being the most ventrally located tract according to various previous studies (Fitzek et al. 2014; Hong et al. 2010; Hua et al. 2012; Standring et al. 2008). Traditionally, the CTS has been functionally associated with voluntary motor control, while FPT and PTT have been linked to modulation of cerebellar function. During the dissection, it was 

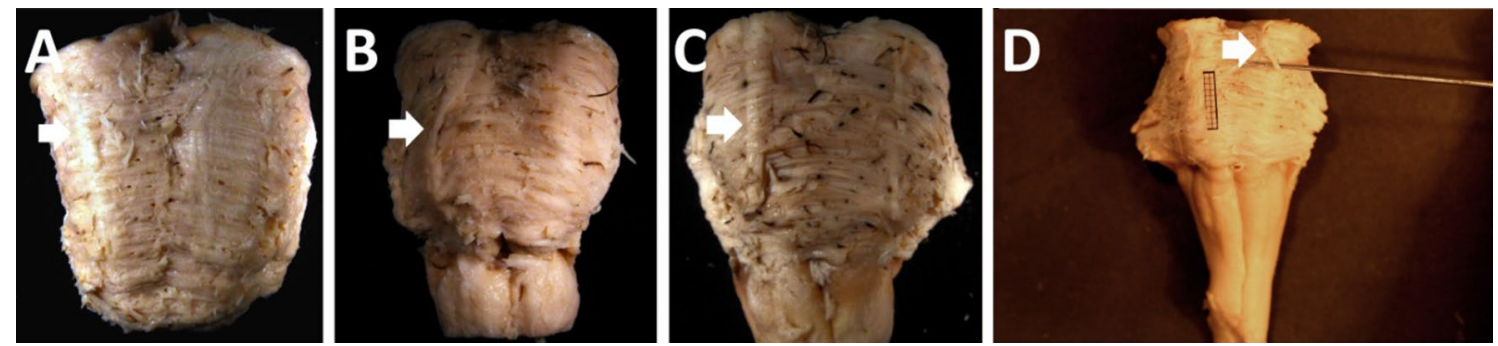

Fig. 3a-d Variations in the course of the superficial longitudinal fascicle (arrow): a medioventral, $\mathbf{b}$ arcing, $\mathbf{c}$ straight, $\mathbf{d}$ lateroventral

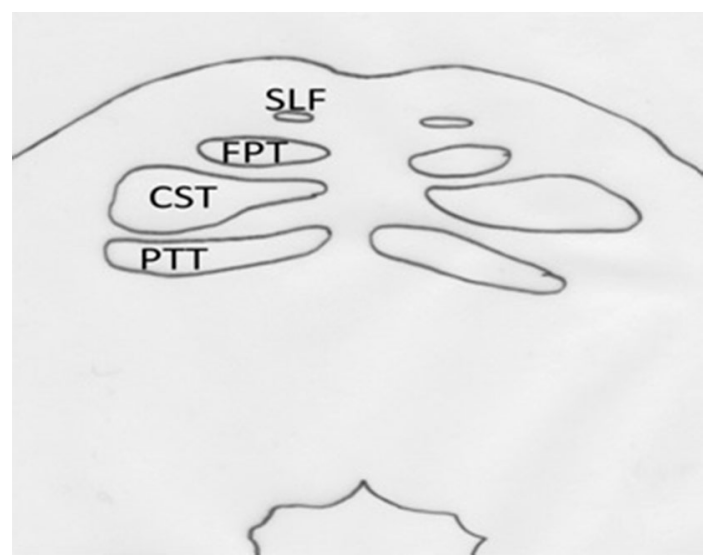

Fig. 4 Visualization of the transverse section of the pons at the level of the medial cerebellar peduncle. SLF superficial longitudinal fascicle, FPT frontopontine tract, CST corticospinal tract, PTT parietotemporopontine tract

clear that the fascicles were connected by minor groups of fibers and so do not constitute separate entities. However, it was difficult to identify the spatial arrangement of these connections using the Klingler method. Serial transverse cross-sections with 3D reconstruction are necessary to visualize the internal structure of the vertical fascicles in the pons. An as-yet undescribed element in the superficial layer of the pons was discovered in the present work: a consistently observed fascicle $(9 / 10$ specimens, $17 / 20$ sides) of vertical fibers located ventrally to the main group of vertical bundles, between superficial transverse fibers. For more than 50 years, this fascicle has been visualized in some neuroanatomical atlases and textbooks without any explanation or comment (Naidich et al. 2009; Peele 1961), whereas in other important academic publications, ranging from the studies of Max Clara to contemporary editions of Gray's anatomy, it has not been visualized at all (Clara 1959; Standring et al. 2008). We therefore propose a name for this fascicle-fasciculus longitudinalis superficialis (superficial longitudinal fascicle; SLF). The functional role of this fascicle remains unclear at this stage of our investigations. This structure should be measured and traced upward to the mesencephalon and the diencephalon, and then downward to the medulla. More detailed studies should show whether it is an independent fascicle of vertical fibers or a portion of frontopontine fibers that become separated from the main fascicle along its pontine course. Localization of SLF part in upper pons corresponds to the localization of fascicle fibers in medial1/5 width of base of the pons (four specimens) or the middle part of the cerebral peduncle. This suggests that it originates in the motor and premotor cortex, a suggestion strengthened by the localization of the SLF in the medial and intermediate group of pontine fibers as described by Benagiano et al., thus making it a part of the cerebrocerebellar circuit (Benagiano et al. 2018). It may also resemble the aberrant pyramidal tract described by Kwon et al. (2011). Observation of its course, especially the ventral direction of its terminal segment, suggests the latter two options. However, the consistent presentation of this structure may indicate that it has a specific function. Our observations are rather incidental, as new studies of the structure of the brain stem using classical anatomical dissection are rare nowadays (Liakos and Koutsarnakis 2016; Skadorwa et al. 2009). While Klingler's technique is archaic, the arrangement of the vertical fascicles of the pons is invisible to standard MRI, meaning that the discovery of such minute structures as the superficial longitudinal fascicle using MRI is currently highly improbable. In conclusion, we can state that the vertical fibers of the ventral pons are arranged in four fascicles: the superficial, frontopontine, corticospinal, and parieto-temporopontine fibers.

\section{Compliance with ethical standards}

Conflict of interest The authors declare they have no conflict of interest.

Open Access This article is distributed under the terms of the Creative Commons Attribution 4.0 International License (http://creativeco mmons.org/licenses/by/4.0/), which permits unrestricted use, distribution, and reproduction in any medium, provided you give appropriate 
credit to the original author(s) and the source, provide a link to the Creative Commons license, and indicate if changes were made.

\section{References}

Benagiano V, Rizzi A, Lorusso L, Flace P, Saccia M, Cagiano R, Ribatti D, Roncali L, Ambrosi G (2018) The functional anatomy of the cerebrocerebellar circuit: a review and new concepts. J Comp Neurol 526(5):769-789

Clara M (1959) Das Nervensystem des Menchen 3rd part. Johann Ambrosius Barth, Leipzig, p 313

De Simone T, Regna-Gladin C, Carriero MR, Farina L, Savoiardo M (2005) Wallerian degeneration of the pontocerebellar fibers. Am J Neuroradiol 26:1062-1065

Fernández-Gil A, Palacios-Bote MR, Leo-Barahona M, Mora-Encinas JP (2010) Anatomy of the brainstem: a gaze into the stem of life. Semin Ultrasound CT MRI 31:196-219

Fitzek C, Weissmann M, Speckter H, Fitzek H, Hopf HC, Shulte E, Stoeter P (2014) Anatomy of brain-stem white-matter tracts shown by diffusion-weighted imaging. Neuroradiology 43:953-960

Hong JH, Son SM, Jang SH (2010) Somatotopic location of corticospinal tract at pons in human brain: a diffusion tensor tractography study. Neuroimage 51:952-955

Hua C, Merchant TE, Gajjar A, Broniscer A, Zhang Y, Li Y, Glenn GR, Kun LE, Ogg RJ (2012) Brain tumor therapy-induced changes in normal appearing brainstem measured with longitudinal diffusion tensor imaging. Int J Radiat Oncol Biol Phys 82(5):2047-2054

Jang SH (2011) Somatotopic arrangement and location of the corticospinal tract in the brainstem of the human brain. Yonsei Med J 52(4):553-557
Kwon HG, Son SM, Chang MC, Kim S, Kwon YH, Jang SH (2011) Characteristics of the aberrant pyramidal tract in comparison with the pyramidal tract in the human brain. BMC Neurosci 12:108. http://www.biomedcentral.com/1471-2202/12/108

Liakos F, Koutsarnakis C (2016) The role of white matter dissection technique in modern neuroimaging: can neuroradiologists benefit from its use? Surg Radiol Anat 38:275

Naidich TP, Duvernoy HM, Delman BN, Sovensen AG, Kollas SS, Hauche EM (2009) Duvernoy's atlas of the human brain stem and cerebellum. Springer, Berlin, p 295

Oh CS, Chung IH, Lee KS, Tanaka S (2003) Morphological study on the rootlets comprising the root of the intermediate nerve. Anat Sci Int 78:111-113

Peele TL (1961) The neuroanatomical basis for clinical neurology, 2nd edn. Blakiston Division, McGraw-Hill, New York

Prats-Galino A, Soria G, de Notaris M, Puig J, Pedraza S (2012) Functional anatomy of subcortical circuits issuing from or integrating at the human brainstem. Clin Neurophysiol 123(4-12):235-240

Skadorwa T, Kunicki J, Nauman P, Ciszek B (2009) Image-guided dissection of human white matter tracts as a new method of modern neuroanatomical training. Folia Morphol 68(3):135-139

Standring S, Borley NR, Collins P, Crossma AR, Gatzulis MA, Healy JC, Johnson D, Mahaderan V, Newell RLM, Wigley CB (2008) Gray's anatomy, 40th edn. Elsevier, Amsterdam, p 281

Virta A, Barnett A, Pierapaoli C (1999) Visualizing and characterizing white matter fiber structure and architecture in human pyramidal tract using diffusion tensor MRI. Magn Reson Imaging 17(8):1121-1133

Zemmoura I (2016) The role of white matter dissection technique in modern neuroimaging: can neuroradiologists benefit from its use? Surg Radiol Anat 38:517 